\title{
Risk factors, ethnic differences and mortality associated with lower-extremity gangrene and amputation in diabetes. The WHO multinational study of vascular disease in diabetes
}

\author{
N. Chaturvedi ${ }^{1}$, LK.Stevens ${ }^{1}$, JH.Fuller ${ }^{1}$, ET. Lee ${ }^{2}$, M. Lu $^{2}$ and the WHO Multinational Study Group* \\ ${ }^{1}$ EURODIAB, Department of Epidemiology and Public Health, University College London, London, UK \\ ${ }^{2}$ Centre for American Indian Health Research and Department of Biostatistics and Epidemiology, College Public Health, \\ University of Oklahoma Health Sciences Centre, Oklahoma City, USA
}

\section{Abstract}

Aims/hypothesis. We aimed to examine geographic differences, risk factors and mortality associated with amputation.

Methods. Data from 10 of the original 14 centres of the WHO Multinational Study of Vascular Disease in Diabetes were used. This included 3443 men and women aged 35 to 55 years at baseline.

Results. Incidences of amputation, adjusted for sex and duration in Type I (insulin-dependent) diabetes mellitus, were 31.0, 8.2, 3.5 and 1.0 per 1000 person years in the American Indian, Cuban, European and East Asian centres respectively. In Type II (non-insulin-dependent) diabetes mellitus, incidences of amputation were 9.7, 2.0, 2.5 and 0.7 per 1000 person years in the American Indian, Cuban, European and East Asian centres respectively. Key risk factors for amputation included glucose, triglyceride, and retinopathy, and were similar for American Indians and Europeans. The age, duration and sex adjusted relative risk for amputation in American Indians compared with
Europeans was 11.48 (95\% CI 3.56, 36.98) in Type I diabetes and 3.86 (95\% CI 2.36, 6.32) in Type II diabetes. Adjusting for heart disease, retinopathy, proteinuria, glucose, blood pressure and triglyceride attenuated these relative risks to 10.83 (95\% CI 3.20, $36.65)$ and $3.15(1.91,5.20)$ in Type I and Type II diabetes respectively. Amputation doubled mortality rates in all groups.

Conclusion/interpretation. Vascular complications and their risk factors are themselves risk factors for amputation in both Type I and Type II diabetes and are common to several geographical regions worldwide. However, reasons for differences between geographical regions and the degree to which different health care systems could be responsible is not clear. [Diabetologia (2001) 44 [Suppl 2]: S 65-S 71]

Keywords Type I (insulin-dependent) diabetes mellitus, Type II (non-insulin-dependent) diabetes mellitus, ethnic groups, amputation, mortality, epidemiology.
People with diabetes have substantially higher rates of lower-extremity gangrene and/or amputation

Corresponding author: Dr N. Chaturvedi, MD; University College London, 1-19 Torrington Place, London, WC1E 6BT, UK

* See reference 9 for list of investigators

Abbreviations: WHO MSVDD; World Health Organization Multinational Study of Vascular Disease in Diabetes; LEG/A, lower extremity gangrene/amputation; SRR, standardized rate ratio; WESDR, Wisconsin Epidemiologic Study of Diabetic Retinopathy.
(LEG/A) than members of the general population $[1,2]$, although there is clear evidence that such a dire consequence of diabetes can in part be prevented $[3,4]$. However, the full aetiology of diabetes related LEG/A remains unclear, therefore it is difficult to design interventions to further reduce risk. Ethnic differences in amputation rates have been observed [1, $2,5,6,19]$ which could reflect true differences in pathophysiology but could also be a consequence of inequalities in access to health care; and the degree to which risk factors for amputation are common for Type I (insulin-dependent) and Type II (non-insulindependent) diabetes mellitus is not certain. 
The WHO Multinational Study of Vascular Disease in Diabetes (WHO MSVDD) offers a unique opportunity to examine the incidence of and risk factors for LEG/A in a number of ethnic and geographically distinct samples of patients with diabetes.

\section{Subjects and methods}

Methods of patient selection and examination for the WHO MSVDD have been described in detail [7, 8] and elsewhere in this supplement [9]. For this analysis the ten participating centres were divided into four geographic or ethnic groups: European, including London, Switzerland, Berlin, Warsaw and Zagreb; East Asian including Hong Kong and Tokyo; American Indian including Oklahoma and Arizona; and Havana.

At the baseline examination, carried out between 1975 and 1977, participants completed a questionnaire which included items on medical history and health-related behaviours. LEG/A was ascertained by questionnaire and examination and was defined as a past history of ischaemic gangrene, or an amputation of toe, foot or leg for arterial obstruction at both baseline and follow-up. The methods of assessing baseline cardiovascular risk factors are described elsewhere [9, 10]. Retinopathy and ECG abnormalities were dichotomised for analysis, i.e. none versus any retinopathy, and no CHD versus any CHD on Minnesota-coded ECGs.

A follow-up morbidity examination was carried out starting in 1983. Incidence of lower-extremity gangrene or amputation was ascertained using information obtained from questionnaires completed at this reexamination or by review of the medical record if the patient could not attend. The date of amputation was also recorded.

Details on the mortality follow-up have been provided [11], and life or death status ascertainment was at least $95 \%$ complete in these centres. Patients were followed-up for this analysis until $1^{\text {st }}$ January 1988.

Statistical analysis. Differences between means and proportions were examined using Students $t$-test and the Chi-square test respectively. Incidence rates were estimated as the number of first LEG/A per 1000 person-years of follow-up, based on all patients who were free of LEG/A at baseline. Earlier presentations from the WHO MSVDD showed large between-centre differences in the prevalence of amputation at baseline [8]. Thus to justify our definition of geographic region, centre and type of diabetes, specific incidence rates were calculated in the first instance. Although numbers were small, between-centre differences indicated that our geographic groupings were appropriate. Amputation risk was consistently higher in men than in women in all subgroups and was strongly related to the duration of diabetes in Type II diabetic patients. As sex distribution and duration of diabetes differed by geographic region, amputation rates were adjusted for these variables using Poisson regression to enable between-region comparisons. Relative risks for potential risk factors were also calculated using Poisson regression techniques. Standardised estimates for relative risks (SRRs) were calculated as the relative risk associated with a one standard deviation change in continuous variables; this ensures that relative risks for continuous variables are directly comparable. Poisson regression techniques were used to compare relative risks for LEG/A between Europeans and Native Americans and to make adjustment for confounders. Due to the skewness of their distributions, the log transfor- mations of serum triglyceride and plasma glucose were used throughout the analyses. A $p$ value of less than 0.05 was considered statistically significant.

\section{Results}

At baseline 4743 patients were examined. Of these 95 had had an amputation and data were missing on 91. Of the remaining 4557, 3443 attended the followup visit and provided complete information as to whether they had had an LEG/A in the intervening period. Those who did not attend for a follow-up visit were in general older, had longer duration of diabetes, had poorer glycaemic control, had a more adverse cardiovascular risk factor profile and were more likely to have microvascular complications at baseline than those who did attend for follow-up.

There were clear differences in age and duration of diabetes at baseline, with patients from Havana having the longest duration of diabetes, but also being the youngest (Tables 1,2 ). In both Type I and Type II diabetic patients, body mass index was highest in American Indians and lowest in East Asians. Triglyceride concentrations were higher in American Indians than Europeans, and American Indians were more likely to have ever smoked. Correspondingly, ECG abnormalities compatible with CHD were more commonly observed in American Indians [9].

Over the average follow-up of 8.9 years LEG/A incidence rates varied considerably by type of diabetes and geographical region (Tables 1,2). In Type I diabetic patients, the highest rates were observed in American Indians, 31.0 per 1000 person years, compared with the East Asian rate of just 1.0 per 1000 person years. Similarly, the highest amputation rate in Type II diabetic patients was also in American Indians, 9.7 per 1000 person years. In East Asians the rate was 0.7 per 1000 person years.

Sufficient numbers to examine risk factor associations within diabetes type and geographical region were only available for Europeans with Type I diabetes and Europeans and American Indians with Type II diabetes.

For European Type I diabetic patients, after adjusting for duration, factors associated with LEG/A incidence were: BMI, presence of retinopathy and ECG changes suggestive of CHD (Table 3). Although numbers were small and results not statistically significant, there was an indication that the risk of amputation was positively related to triglyceride concentrations. For Type II diabetic patients after adjusting for duration of diabetes, baseline risk factors found to be associated with LEG/A incidence were, for the Europeans, serum triglyceride, plasma glucose, proteinuria and retinopathy. For American Indians, factors associated with risk of amputation were: cholesterol, serum triglyceride, 
Table 1. Comparison of baseline data by geographical region for patients with Type I (insulin-dependent) diabetes mellius

\begin{tabular}{|c|c|c|c|c|}
\hline & $\begin{array}{l}\text { European } \\
(N=689) \\
\text { Mean }(95 \% \mathrm{CI})\end{array}$ & $\begin{array}{l}\text { East Asian } \\
(N=101) \\
\text { Mean }(95 \% \mathrm{CI})\end{array}$ & $\begin{array}{l}\text { American Indian } \\
(N=34) \\
\text { Mean }(95 \% \mathrm{CI})\end{array}$ & $\begin{array}{l}\text { Havana } \\
(N=56) \\
\text { Mean }(95 \% \mathrm{CI})\end{array}$ \\
\hline Age, years & $43.9(43.4,44.3)$ & $46.9(45.8,48.0)^{\mathrm{a}}$ & $44.4(42.5,46.3)$ & $42.1(40.7,43.4)$ \\
\hline Systolic blood pressure, $\mathrm{mmHg}^{\mathrm{d}}$ & $133(132,135)$ & $135(131,139)$ & $135(129,142)$ & $135(130,140)$ \\
\hline $\mathrm{BMI}, \mathrm{Kg} / \mathrm{ml}^{2 \mathrm{~d}}$ & $24.2(24.0,24.5)^{\mathrm{c}}$ & $22.3(21.6,23.0)^{\mathrm{c}}$ & $31.6(30.2,32.6)$ & $23.8(23.0,24.7)^{\mathrm{c}}$ \\
\hline Serum cholesterol $^{\mathrm{d}}$ & $5.87(5.79,5.97)$ & $5.08(4.85,5.31)$ & $5.56(5.18,5.97)$ & $6.08(5.79,6.36)$ \\
\hline Plasma glucose $\mathrm{de}^{\mathrm{de}}$ & $n(\%)$ & $n(\%)$ & $n(\%)$ & $n(\%)$ \\
\hline Number of men & $326(47)$ & $51(51)$ & $17(50)$ & $30(54)$ \\
\hline Ever smoked $^{\mathrm{d}}$ & $414(61)$ & $47(44)^{c}$ & $25(74)$ & $31(48)^{b}$ \\
\hline Light or heavy proteinuria ${ }^{\mathrm{d}}$ & $146(21)$ & $24(25)$ & $6(35)$ & $12(21)$ \\
\hline Retinopathy present ${ }^{\mathrm{d}}$ & $335(48)$ & $34(37)$ & $6(35)$ & $27(43)$ \\
\hline
\end{tabular}

Table 2. Comparison of baseline data by geographical region for patients with Type II (non-insulin-dependent) diabetes mellitus

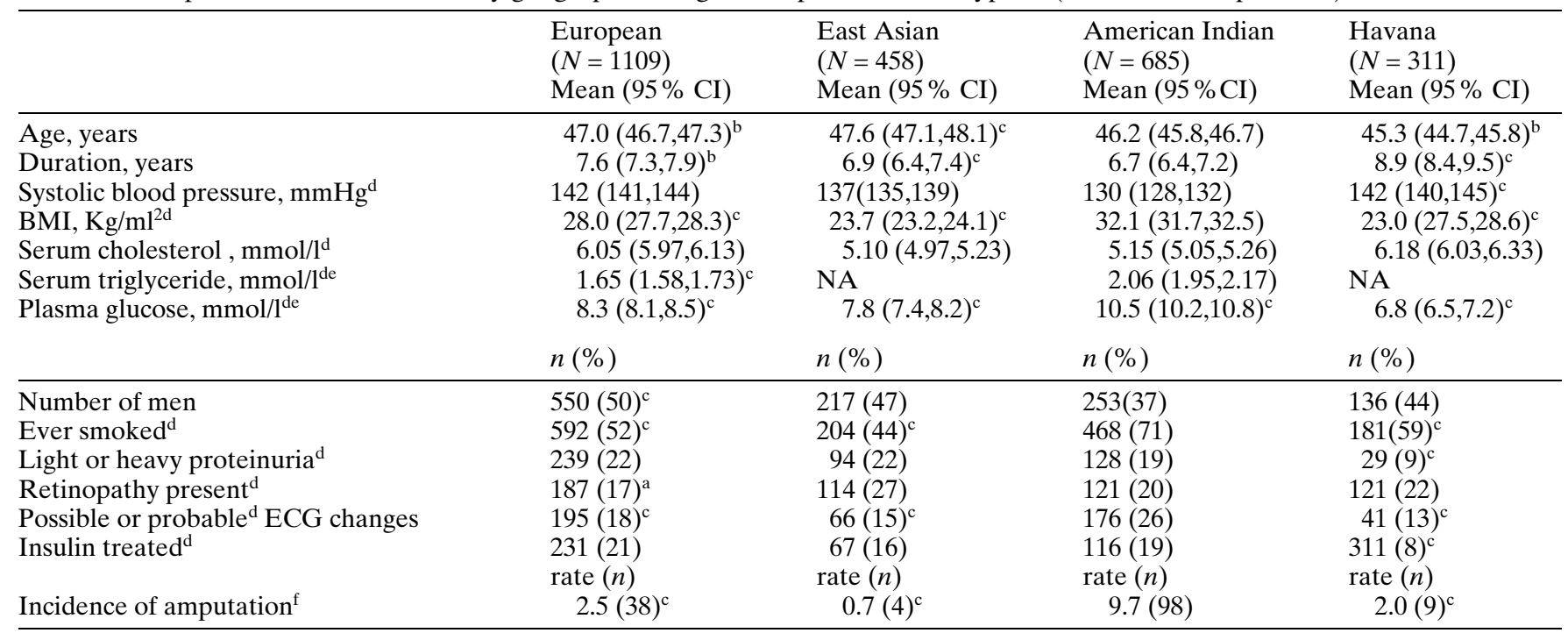

Significantly different from American Indians with ${ }^{\mathrm{a}} p<0.05$;

${ }^{\mathrm{b}} p<0.01 ;{ }^{\mathrm{c}} p<0.001$;

$\mathrm{d}$ means and percentages are adjusted for duration of diabetes

e geometric mean;

$\mathrm{f}$ per 1000 person years, adjusted for duration of diabetes and and sex; sex

plasma glucose and retinopathy (Table 4). Although amputation rates were higher in those with ischaemic ECG changes compared to those without, these differences did not achieve significance in either geographical region.

The relative risks for amputation were over eight and three times greater in American Indians compared with Europeans in Type I (8.63, $95 \%$ CI 3.50, 21.29) and Type II diabetic $(3.87,95 \%$ CI $2.64,5.67)$ patients respectively (adjusted for age, diabetes duration and sex). Table 5 shows the effect of proposed risk factors on this relative risk. To ensure that models are comparable, only those with complete data on all potential confounders were included in this analysis; thus the basic relative risks for comparison differ from those given above. Out of 718 potential Type I diabetic patients with complete data on age, sex, and diabetes duration, only 324 could be included in these analyses. Similarly, in Type II diabetic patients, out of 1789 potential patients, only 1017 could be included. However, a comparison of baseline risk factors for those with full data and those with data 
Table 3. Duration adjusted incidence of lower-extremity gangrene and amputation and the relative risk (RR) associated with baseline risk factors for European patients with Type I (insulin-dependent) diabetes mellitus

\begin{tabular}{|c|c|c|c|}
\hline & $n^{\mathrm{a}}$ & Rate $^{\mathrm{b}}$ & $\begin{array}{l}\text { Relative } \\
\text { Risk } \\
(95 \% \text { CI })\end{array}$ \\
\hline \multicolumn{4}{|c|}{ Systolic blood pressure, $\mathrm{mmHg}$} \\
\hline$<128$ & 8 & 3.6 & 1 \\
\hline $128-145$ & 10 & $4.51 .3(0.5,3.2)$ & \\
\hline $146+$ & 9 & 6.0 & $1.8(0.7,4.8)$ \\
\hline SRR (95\% CI) & $1.3(0.9,1.9)$ & & \\
\hline$p$-value ${ }^{c}$ & 0.10 & & \\
\hline \multicolumn{4}{|c|}{ Serum cholesterol, mg/dl (mmol/1) } \\
\hline$<197(<5.1)$ & 3 & 2.5 & 1 \\
\hline $198-(5.1-)$ & 10 & 5.2 & $2.0(0.6,7.5)$ \\
\hline $239+(6.2+)$ & 11 & 5.2 & $2.1(0.6,7.4)$ \\
\hline SRR (95\% CI) & $1.4(1.0,1.9)$ & & \\
\hline$p$ value $^{\mathrm{c}}$ & 0.08 & & \\
\hline \multicolumn{4}{|c|}{ Serum triglyceride $(\mathrm{mmol} / \mathrm{l})$} \\
\hline$<1.26$ & 9 & 4.5 & 1 \\
\hline $1.26-$ & 7 & 6.8 & $1.5(0.4,3.9)$ \\
\hline $2.10+$ & 4 & 9.3 & $2.0(0.6,6.6)$ \\
\hline SRR (95\% CI) & $1.2(0.8,1.9)$ & & \\
\hline$p$ value $^{\mathrm{c}}$ & 0.40 & & \\
\hline \multicolumn{4}{|c|}{ Plasma glucose (mmol/l) } \\
\hline$<7.48$ & 3.55 & 5.5 & 1 \\
\hline $7.48-$ & 4 & 5.8 & $1.0(0.2,4.7)$ \\
\hline $11.83+$ & 8 & 4.3 & $0.7(0.2,2.8)$ \\
\hline $\operatorname{SRR}\left(95^{\circ} \% \mathrm{CI}\right)$ & $1.2(0.7,2.1)$ & & \\
\hline$p$ value $^{\mathrm{c}}$ & 0.6 & & \\
\hline \multicolumn{4}{|c|}{ Body mass index, $\mathrm{Kg} / \mathrm{m}^{2}$} \\
\hline$\leq 21$ & 10 & 12.5 & 1 \\
\hline $21.1-22.5$ & 3 & 2.7 & $0.2(0.1,0.8)$ \\
\hline $22.6-24.9$ & 6 & 3.3 & $0.3(0.1,0.7)$ \\
\hline $25+$ & 8 & 4.3 & $0.3(0.1,0.9)$ \\
\hline SRR (95 \% CI) & $0.7(0.4,1.1)$ & & \\
\hline$p$ value & 0.08 & & \\
\hline \multicolumn{4}{|l|}{ Smoking } \\
\hline Never smoked & 14 & 6.3 & 1 \\
\hline Ever smoked & 13 & 3.6 & $0.6(0.3,1.3)$ \\
\hline \multicolumn{4}{|l|}{ Proteinuria } \\
\hline None & 18 & 4.1 & 1 \\
\hline Light or heavy & 8 & 5.9 & $1.6(0.7,3.7)$ \\
\hline \multicolumn{4}{|l|}{ Retinopathy } \\
\hline Absent & 8 & 2.8 & 1 \\
\hline Present & 18 & 5.7 & $2.4(1.0,5.9)$ \\
\hline \multicolumn{4}{|l|}{ ECG } \\
\hline Normal & 18 & 3.7 & 1 \\
\hline \multicolumn{4}{|c|}{ Probable or possible } \\
\hline changes & 9 & 12.2 & $3.3(1.5,7.4)$ \\
\hline
\end{tabular}

a Number of new cases of amputation;

${ }^{\mathrm{b}}$ Rate per 1000 person years are adjusted for duration;

${ }^{c} p$ value relates to the significance of the risk factor as a continuous variable

on age, diabetes duration and sex showed no differences. Relative risks between Europeans and American Indians altered from 8.63 to 11.48 in those without and with complete data; in Type II diabetic patients, these figures were 3.87 and 3.86. For Type I diabetic patients, the inclusion of proteinuria was the strongest single contributing factor for the increased risk of amputation in American Indians, changing the relative risk from 11.48 to 9.58 . However, even after including all available possible risk factors, American Indians were still 8.77 times more likely to have an amputation than Europeans. For Type II diabetic patients, all factors seemed to have approximately equivalent effects accounting for the geographical difference; the strongest factor found was plasma glucose. Inclusion of all risk factors barely attenuated the relative risk of amputation, from 3.86 to 3.15.

Mortality rates for those ascertained as amputees in 1983 were compared with patients examined in 1983 but without amputation, by geographical region. Although numbers were small, mortality rates were approximately doubled in those with amputation in 1983 compared with those without, but reflected the underlying mortality rate in that population (Table 6).

\section{Discussion}

The WHO MSVDD is one of the few studies to examine differences in amputation rate and risk factors by diabetes type and geographical region.

The main risk factors for amputation in Type I diabetic patients were other vascular complications, especially retinopathy and CHD. Much weaker associations were observed with serum cholesterol and triglyceride, and no associations with glucose or smoking. The high rate of amputation in the leanest Europeans $(\mathrm{BMI}<21$ ) was probably due to subclinical disease, resulting in a low BMI and high risk of complications and death [12]. These findings do not entirely accord with the Wisconsin Epidemiologic Study of Diabetic Retinopathy (WESDR), which showed that blood pressure and glycated haemoglobin were related to amputation risk, but that nephropathy or retinopathy were at most only weakly correlated [13]. The follow-up for the WESDR at 4 years was half that of our study. The ability of a continuous and mutable variable to predict risk attenuates with time, perhaps explaining the weak associations observed in the WHO MSVDD for cholesterol, triglyceride, blood pressure and glucose.

In Type II diabetic patients, key risk factors for amputation in Europeans and American Indians, apart from diabetes duration, were retinopathy, glucose and triglyceride. Proteinuria was related to amputation risk only in Europeans. These findings are in closer agreement with previous observations of United States or European white populations [13-15], and American Indians [2, 6]. In contrast to Type I diabetes, the closer association of diabetes duration rather than age with amputation, and the stronger association with glycaemia could reflect a greater pathogenetic role for hyperglycaemia, probably via neuropathy and peripheral vascular disease. 
Table 4. Duration adjusted incidence of lower-extremity gangrene and amputation and the relative risk (RR) associated with baseline risk factors for European and American Indian patients with Type II (non-insulin-dependent) diabetes mellitus

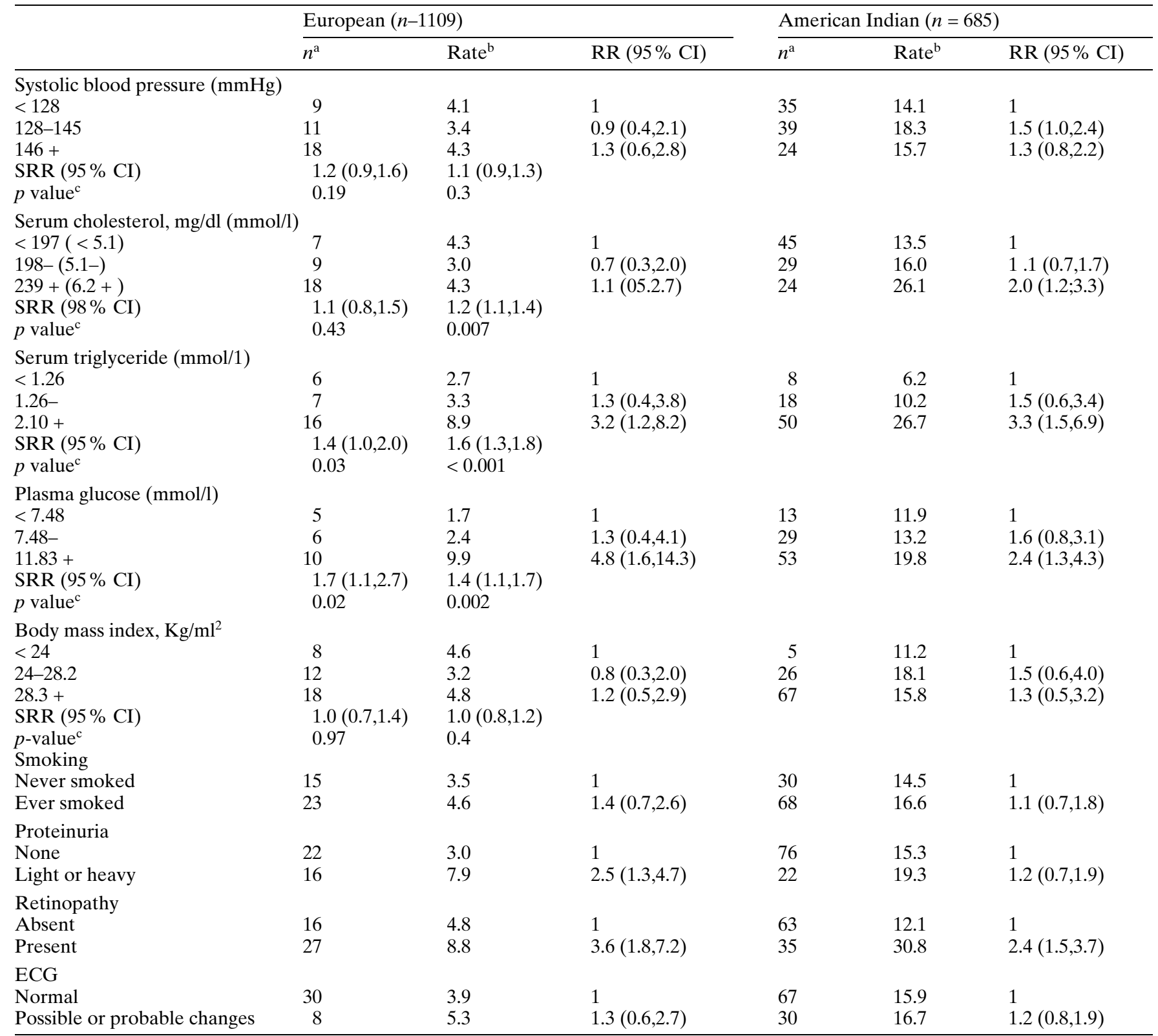

${ }^{a}$ Number of new cases of amputation;

${ }^{\mathrm{b}}$ Rate per 1000 person years are adjusted for duration;

${ }^{\mathrm{c}} p$ value relates to the significance of the risk factor as a continuous variable associated

The association of amputation with nephropathy and retinopathy, both related to glycaemic control, also suggests that hyperglycaemia is causally important in amputation. Associations with smoking have been absent or weak. This could result from the low prevalence of smoking in some populations [2], the grouping of ex-smokers and current smokers [14] or the general misclassification bias associated with self-reports of smoking. Surprisingly, we showed very little association with prevalent CHD at baseline. Efforts to improve glycaemic control and general health care could be intensified as a consequence of CHD and thus result in a reduced risk of amputation. Fur- thermore, it is possible that the impact of smoking on vascular disease is overwhelmed by the more powerful metabolic risk factors.

In Type I and Type II diabetic patients, American Indians had strikingly higher rates of amputation than Europeans. Some, but not all of the main risk factors were less favourable in American Indians, but even after adjustment, relative risks remained high. The increased risk in American Indians has been reported previously $[2,6]$ but this is the first time that direct, between-ethnic-group comparisons have been made. Rates were higher in Oklahoma Indians than in Pima Indians [6] and it was hypothesis- 
Table 5. Risk of incidence of LEG/A for American Indians relative to that for Europeans

\begin{tabular}{|c|c|c|c|c|}
\hline \multirow[b]{2}{*}{ Model } & \multicolumn{2}{|c|}{ Type I diabetic patients (324) } & \multicolumn{2}{|c|}{ Type II diabetic patients (1070) } \\
\hline & Relative risk & $(95 \% \mathrm{CI})$ & Relative risk & $(95 \% \mathrm{CI})$ \\
\hline Age, duration of diabetes and sex & 11.48 & $(3.56,36.98)$ & 3.86 & $(2.36,6.32)$ \\
\hline Age, duration of diabetes, sex and plasma glucose & 11.42 & $(3.57,36.53)$ & 3.10 & $(1.87,5.14)$ \\
\hline Age, duration of diabetes, sex and systolic blood pressure & 10.98 & $(3.42,35.28)$ & 4.09 & $(2.49,6.73)$ \\
\hline Age, duration of diabetes, sex and serum triglyceride & 10.83 & $(3.20,36.65)$ & 3.15 & $(1.91,5.20)$ \\
\hline $\begin{array}{l}\text { Age duration of diabetes, sex, ECG, plasma glucose, } \\
\text { systolic blood pressure, proteinuria, retionopathy, triglyceride }\end{array}$ & 8.77 & $(2.76,27.91)$ & 2.78 & $(1.66,4.66)$ \\
\hline
\end{tabular}

Table 6. Mortality rates per 1000 person years in people with and without amputation by diabetes type and ethnic group

\begin{tabular}{lcll}
\hline & Europeans & $\begin{array}{l}\text { American } \\
\text { Indians } \\
(n)\end{array}$ & Havana \\
& $(n)$ & $(n)$ \\
\hline $\begin{array}{l}\text { Type I diabetes } \\
\text { Without amputation }\end{array}$ & $10.3(71)$ & $11.7(3)$ & $16.4(9)$ \\
$\begin{array}{l}\text { With amputation } \\
\text { Type II diabetes }\end{array}$ & $24.0(6)$ & $43.5(5)$ & $37.9(2)$ \\
$\begin{array}{l}\text { Without amputation } \\
\text { With amputation }\end{array}$ & $6.4(72)$ & $11.8(75)$ & $11.8(39)$ \\
\hline
\end{tabular}

ed that routine examinations were more frequent in the Pima group, so that foot lesions were detected and treated earlier in the course of disease, avoiding the need for amputation. Amputation rates in diabetic Pimas however, are substantially higher than United States whites [16]. This could have resulted from differences in study populations, with the white group having a greater proportion of people without complications but also because of their quarterly frequency of re-examination, which reduces the risk of amputation. In the WHO MSVDD study, given that numbers were relatively small, there were no striking differences in risk factor associations for amputation in American Indians and Europeans. This again suggests that the pathogenesis of amputation is not different but that access to health care, by direct effects on the foot and by glycaemic control, could explain the ethnic differences observed. However, quality of health care might not be the full reason for ethnic differences in amputation rates. A comparison of diabetes in African Americans, Hispanics and non-Hispanic whites showed an equivalent amputation rate in the Hispanics and non-Hispanic whites, with higher rates only in the African Americans, even though the quality of health care is comparatively poorer for both African Americans and Hispanics than for non-Hispanic whites [5,17]. High quality foot care can reduce the risk of amputation, by between $44 \%$ and $85 \%$ [18] and if the pathogenesis of amputation is similar for all ethnic groups, there are clear opportunities to reduce ethnic differences in diabetes related amputation.

Mortality rates in those who had had an amputation were approximately twice as high in all ethnic or geographic groups than those who were not amputated. Others have also shown an increased mortality risk in diabetic amputees, ranging from a 1.5-fold to 7.0 -fold increase in risk $[2,6]$.

There are several limitations of the WHO dataset for this analysis. Despite a reasonably large cohort, the numbers of amputee patients were relatively small. Patients with amputations due only to arterial disease were included, but because of the difficulty in differentiating neuropathic and arterial reasons for amputation, some misclassification could have occurred. Furthermore, we did not collect any data on neuropathy, we had limited data on vascular disease at baseline, and there were no data on chronic foot ulceration. These are important risk factors for LEG/A but in general, many of these are consequences of poor glycaemic control, on which we do have some data. We also did not have data on access to or quality of health care, again an important determinant of amputation risk. Only those patients who had complete data at baseline and follow-up could be included in these analyses, which could have resulted in important biases. However, a baseline comparison of those who were with those who were not included in these analyses indicates that risk factor profiles were worse and mortality rates were higher in those who were not included in these analyses. It is likely that non-attendees had higher amputation rates and poorer survival than followup patients. Thus calculated incidence rates and risk factor associations are probably underestimated. Despite these limitations, this is one of the largest cohort studies to examine diabetes-related LEG/A and has the added advantage of comparing differences by diabetes type and geographical region in a single study. Our findings confirm many of those from other studies, with additional information on 
the reasons for between-region variations in incidence.

We conclude that the risk of amputation in people with diabetes is related to other vascular complications, indicating a role for hyperglycaemia. But clear geographic differences in amputation risk cannot wholly be accounted for by existing risk factors. A clear candidate is access and quality of health care, which substantially influences amputation risk.

\section{References}

1. Most RS, Sinnock P (1983) The epidemiology of lower extremity amputations in diabetic individuals. Diabetes Care 6: 87-91

2. Nelson RG, Gohdes DM, Everhart JE et al. (1988) Lower-extremity amputations in Type II diabetes. 12-yr follow-up study in Pima Indians. Diabetes Care 11: 8-16

3. Lippman HI (1979) Must loss of limb be a consequence of diabetes mellitus? Diabetes Care 2: 432-436

4. Litzelman DK, Slemenda CW, Langefeld CD et al. (1993) Reduction of lower extremity clinical abnormalities in patients with non-insulin-dependent diabetes mellitus. A randomized, controlled trial. Ann Intern Med 119: 36-41

5. Lavery LA, Ashry HR, van Houtum W, Pugh JA, Harkless LB, Basu S (1996) Variation in the incidence and proportion of diabetes-related amputations in minorities. Diabetes Care 19: 48-52

6. Lee JS, Lu M, Lee VS, Russell D, Bahr C, Lee ET (1993) Lower extremity amputation. Incidence, risk factors, and mortality in the Oklahoma Indian Diabetes Study. Diabetes 42: 876-882

7. Jarrett RJ, Keen H, Grabauskas V (1979) The WHO Multinational Study of Vascular Disease in Diabetes: 1 . General Description. Diabetes Care 2: 175-186

8. Diabetes Drafting Group (1985) Prevalence of small vessel and large vessel disease in diabetic patients from 14 centres. The World Health Organisation Multinational Study of Vascular Disease in Diabetics. Diabetologia 28: 615-640

9. Lee ET, Keen H, Bennett PH, Fuller JH, Lu M, and the WHO Multinational Study Group (2001) Follow-up of the WHO Multinational Study of Vascular Disease in Diabetes: general description and morbidity. Diabetologia 44 [Supp 2]: S3-S13

10. West KM, Ahuja MMS, Bennett PH, Czyzyk A, De Acosta OM, Fuller JH, Grab B, Grabauskas V, Jarrett J, Kosaka K, Keen H, Krolewski AS, Miki E, Schliack V, Teuscher A, Watkins P, Stober JA (1983) The role of circulating glucose and triglyceride concentrations and their interactions with other "risk factors" as determinants of arterial disease in nine diabetic population samples from the WHO Multinational Study. Diabetes Care 6: 361-369

11. Morrish NJ, Wang S-L, Fuller JH, Keen H, and the WHO Multinational Study Group (1999) Mortality and causes of death in the WHO Multinational Study of Vascular Disease in Diabetes. Diabetologia 44 [Supp 2]: S14-S 21

12. Chaturvedi N, Fuller J (1995) Mortality Risk by Body Weight and Weight Change in People With Type II diabetes. Diabetes Care 18: 766-774

13. Moss SE, Klein R, Klein BEK (1992) The prevalence and incidence of lower extremity amputation in a diabetic population. Arch Intern Med 152: 610-616

14. Lehto S, Ronnemaa T, Pyorala K, Laakso M (1996) Risk factors predicting lower extremity amputations in patients with Type II diabetes. Diabetes Care 19: 607-612

15. Selby JV, Zhang D (1995) Risk factors for lower extremity amputations in persons with diabetes. Diabetes Care 18: 509-516

16. Kreines K, Johnson E, Albrink M et al. (1985) The course of peripheral vascular disease in non-insulin-dependent diabetes. Diabetes Care 8: 235-243

17. Reiber GE, Pecorraro RE, Koepsell TD (1992) Risk factors for amputation in patients with diabetes mellitus: a case-control study. Ann Intern Med 117: 97-105

18. Bild DE, Selby JV, Sinnock P, Browner WS, Braveman P, Showstack JA (1989) Lower-extremity amputation in people with diabetes: epidemiology and prevention. Diabetes Care 12: 24-31

19. Adler AI, Boyko EJ, Ahroni JH, Smith DG (1999) Lowerextremity amputation in diabetes. The independent effects of peripheral vascular disease, sensory neuropathy and foot ulcers. Diabetes Care 22: 1029-1035 